\title{
Acetylation of the Amino Group on Guanosine Induced by Nitric Oxide in Acetonitrile under Aerobic Conditions
}

\author{
Toshinori SuzuKI, ${ }^{*}$ Toshimitsu FuKaI, ${ }^{1)}$ Yusuke SeKI, and Michiyo INUKaI \\ School of Pharmacy, Shujitsu University; Okayama 703-8516, Japan. \\ Received August 25, 2008; accepted October 24, 2008; published online October 31, 2008
}

\begin{abstract}
When nitric oxide was bubbled into acetonitrile under aerobic conditions, the solution showed a cobalt-blue color. Addition of guanosine into the solution generated $N^{2}$-acetylguanosine as a major product. The result of the reaction using ${ }^{15} \mathrm{~N}$ labeled acetonitrile indicated that the nitrogen atom of the acetylated exocyclic amino group on $N^{2}$-acetylguanosine originated from acetonitrile. We discuss the reaction mechanism for the acylation.
\end{abstract}

Key words nitric oxide; acetonitrile; acetylation; guanosine

\section{Results and Discussion}

Nitric oxide (NO) is synthesized in various types of cells by the enzyme nitric oxide synthase and is involved in numerous biological functions including vasodilation, neurotransmission, and inflammation. ${ }^{2,3)}$ Although NO is a radical, the reactivity of NO per se is relatively low. ${ }^{4)}$ However, in the presence of $\mathrm{O}_{2}$, NO is converted to a reactive nitrosating reagent, dinitrogen trioxide $\left(\mathrm{N}_{2} \mathrm{O}_{3}\right){ }^{5)} \mathrm{N}_{2} \mathrm{O}_{3}$ can react with amino groups in various biological molecules resulting in corresponding $\mathrm{N}$-nitroso compounds. Amino groups of nucleic acid components react with $\mathrm{N}_{2} \mathrm{O}_{3}$ resulting in deamination compounds, ${ }^{6,7)}$ since the formed $N$-nitroso compounds are unstable and subsequent hydrolyses are performed. Suzuki et al. reported that $\mathrm{N}_{2} \mathrm{O}_{3}$ converted guanosine (Guo) into the novel compound oxanosine (Oxo) in addition to the well-known deamination compound xanthosine (Xao). ${ }^{8)} \mathrm{A}$ possible overall reaction pathway of Guo with $\mathrm{N}_{2} \mathrm{O}_{3}$ generating Xao and Oxo was proposed as follows. ${ }^{9,10)} \mathrm{N}_{2} \mathrm{O}_{3}$ reacts with the amino group on $\mathrm{C} 2$ of Guo, resulting in the $N^{2}$-nitroso intermediate. The nitroso intermediate is converted immediately to the diazoate intermediate $\left(-\mathrm{N}=\mathrm{N}-\mathrm{O}^{-}\right)$, which appears to be the most stable intermediate throughout the reaction pathway. Then the diazoate intermediate is converted to the diazonium intermediate $\left(-\mathrm{N}_{2}^{+}\right)$and the ring-opened cation is formed synchronously by the release of a nitrogen molecule from the diazonium. Reaction by $\mathrm{H}_{2} \mathrm{O}$ on the carbodiimide $(-\mathrm{N}=\mathrm{C}=\mathrm{N}-)$ of the ring-opened cation and subsequent ring closure and tautomerization generates Xao. In contrast, reaction by $\mathrm{H}_{2} \mathrm{O}$ on the carbonyl group of the ringopened cation and subsequent ring closure generates Oxo. Lucas et al. reported that $N$-nitrosoindoles, which are NO donors, also induced generation of Xao and Oxo from Guo in neutral solution including $50 \%$ acetonitrile $\left(\mathrm{CH}_{3} \mathrm{CN}\right) .{ }^{11)}$ In addition, $N^{2}$-acetylguanosine $\left(N^{2}\right.$-Ac-Guo) was generated as

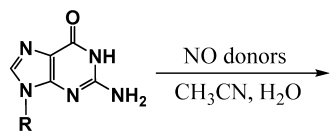

Guo

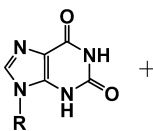

Xao

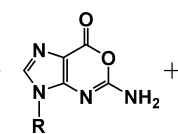

Oxo

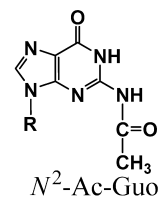

R; ribose
Chart 1. Reaction Scheme and Structures of the Products in the Reaction of Guo with NO Donors in $\mathrm{CH}_{3} \mathrm{CN} / \mathrm{H}_{2} \mathrm{O}=1 / 1(\mathrm{v} / \mathrm{v})$

$\mathrm{R}$ in the structure denotes a ribose moiety. a co-product in the reaction mixture (Chart 1). However, the reaction mechanism of the acetylation of the amino group induced by $\mathrm{NO}$ in $\mathrm{CH}_{3} \mathrm{CN}$ is unclear. In the present study, we studied the acetylation of the exocyclic amino group on Guo by $\mathrm{NO}$ and $\mathrm{CH}_{3} \mathrm{CN}$ under aerobic conditions. From the results of the reactions using $N^{2}$-methylguanosine $\left(N^{2}-\mathrm{Me}\right.$ Guo) and ${ }^{15} \mathrm{~N}$ labeled acetonitrile $\left(\mathrm{CH}_{3} \mathrm{C}^{15} \mathrm{~N}\right)$, the reaction mechanism for the acylation is proposed.

$\mathrm{NO}$ gas $(4 \mathrm{ml} / \mathrm{min})$ was bubbled into $2 \mathrm{ml} \mathrm{CH}_{3} \mathrm{CN}$ in an open vessel at ambient temperature in open air. By $10 \mathrm{~min}$ NO bubbling, the solution showed a cobalt-blue color. The visible light spectrum of the solution with the absorbance peak maximum of $661 \mathrm{~nm}$ is shown in Fig. 1. It was similar to the reported spectrum of $\mathrm{N}_{2} \mathrm{O}_{3}$ in organic solvents. ${ }^{12,13}$ The cobalt-blue color disappeared within $30 \mathrm{~min}$ when the solution was left without a cap at ambient temperature. However, the color was maintained at least for one month in the vessel with a cap. Under Ar atmosphere, NO gas bubbling into $\mathrm{CH}_{3} \mathrm{CN}$ did not change the color. These results suggest that $\mathrm{NO}$ reacts with $\mathrm{O}_{2}$ in the air generating $\mathrm{N}_{2} \mathrm{O}_{3}$ in $\mathrm{CH}_{3} \mathrm{CN}$, and that $\mathrm{N}_{2} \mathrm{O}_{3}$ can exist stably in $\mathrm{CH}_{3} \mathrm{CN}$. When $10.0 \mathrm{mg}$ $(35.3 \mu \mathrm{mol})$ Guo was added into the $\mathrm{N}_{2} \mathrm{O}_{3} / \mathrm{CH}_{3} \mathrm{CN}$ solution, Guo dissolved generating a gas. The solution in the open vessel was left for $10 \mathrm{~min}$ at ambient temperature. Figure 2 shows the reversed phase HPLC (RP-HPLC) chromatogram of the reaction mixture. Guo eluted at an HPLC retention time of 13.7 min with $\lambda_{\max }=253 \mathrm{~nm}$ in the on-line detected UV spectrum disappeared completely: The peak around $13.7 \mathrm{~min}$, actually at $13.6 \mathrm{~min}$, in the chromatogram of the reaction mixture showed a different UV spectrum with $\lambda_{\max }=261$ and $284 \mathrm{~nm}$. A product (compound 1) eluted at an

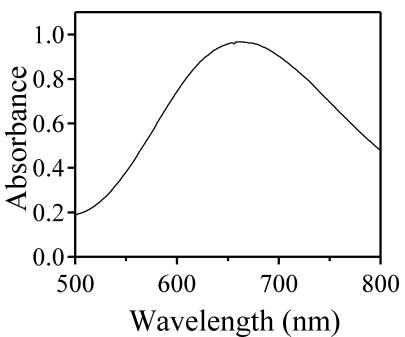

Fig. 1. UV Spectrum of the $\mathrm{NO}$ Bubbled Solution of $\mathrm{CH}_{3} \mathrm{CN}$

$\mathrm{NO}$ gas $(4 \mathrm{ml} / \mathrm{min})$ was bubbled into $2 \mathrm{ml} \mathrm{CH}_{3} \mathrm{CN}$ in an open vessel at ambient temperature for $10 \mathrm{~min}$ under aerobic conditions. The flow rate of NO gas $(99.7 \%$, Sumitomo Seika, Tokyo) was controlled by a Model 3660 mass flow controller (KOFLOC, Kyoto, Japan). 


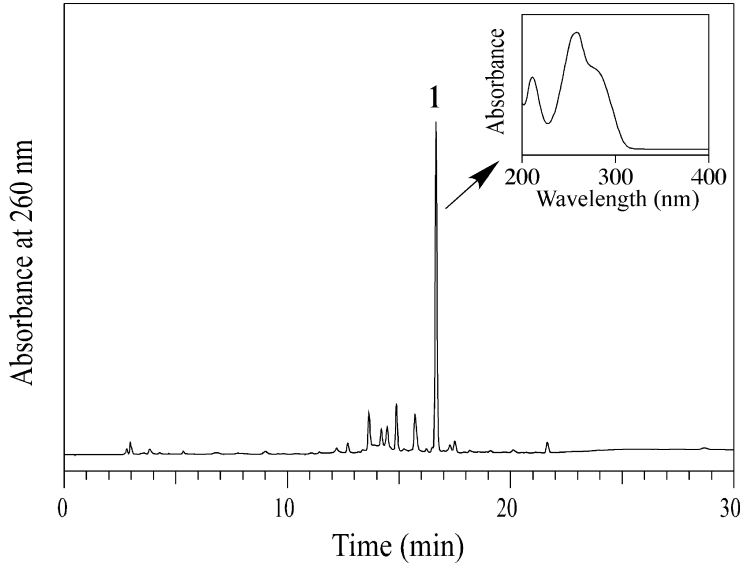

Fig. 2. RP-HPLC Chromatogram of a Reaction Solution of Guo with $\mathrm{N}_{2} \mathrm{O}_{3} / \mathrm{CH}_{3} \mathrm{CN}$

The insets are the on-line UV spectrum of 1 . Guo $(10 \mathrm{mg})$ was added to the $\mathrm{N}_{2} \mathrm{O}_{3} / \mathrm{CH}_{3} \mathrm{CN}$ solution. The reaction mixture in the open vessel was left to stand for $10 \mathrm{~min}$ at ambient temperature. The RP-HPLC chromatogram was detected at $260 \mathrm{~nm}$. Guo eluted at an HPLC retention time of $13.7 \mathrm{~min}$ with $\lambda_{\mathrm{max}}=253 \mathrm{~nm}$ in the on-line detected UV spectrum was disappeared completely: The peak around 13.7 min, actually at $13.6 \mathrm{~min}$, in this chromatogram showed a different UV spectrum with $\lambda_{\max }=261$ and $284 \mathrm{~nm}$.
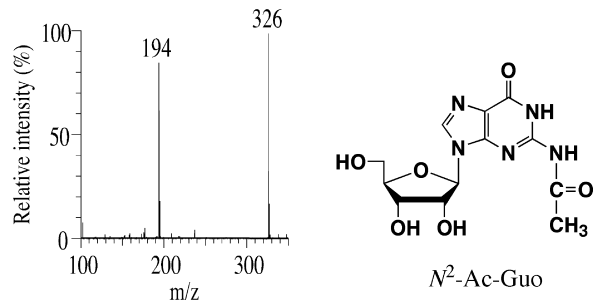

Fig. 3. Positive-Ion Electrospray Ionization Time of Flight Mass Spectrometry Spectrum (ESI-TOF/MS) of 1 and the Structure of $N^{2}$-Ac-Guo

The sample isolated by RP-HPLC was directly infused into the MS system (MicroTOF, Bruker, Bremen, Germany) by a syringe pump without a column.

HPLC retention time of $16.7 \mathrm{~min}$ showed a $\lambda_{\max }=259 \mathrm{~nm}$ in the on-line detected UV spectrum (Fig. 2, inset). The product was collected by RP-HPLC and subjected to MS and NMR measurements. Figure 3 shows an ESI-TOF/MS spectrum of the product. Two major peaks, $m / z 326$ and 194, which are attributable to the molecular ion and the base fragment ion, respectively, were observed. ${ }^{1} \mathrm{H}-\mathrm{NMR}$ showed a set of signals of intact ribose protons and $\mathrm{H} 8$ aromatic proton. In addition, two imino protons and three protons on a methyl group were observed. Combining these spectrometric data, the product was identified as $N^{2}$-acetylguanosine $\left(N^{2}\right.$-Ac-Guo). These spectrometric data accorded well with the reported data of $N^{2}$-Ac-Guo. ${ }^{14)}$ The $N^{2}$-Ac-Guo purified by RP-HPLC was $3.1 \mathrm{mg}(9.5 \mu \mathrm{mol}$, yield: $27 \%)$.

Concerning the mechanism of $N^{2}$-Ac-Guo formation, two conceivable pathways exist (Chart 2). In Path $\mathrm{I}, \mathrm{N}_{2} \mathrm{O}_{3}$ initially reacts with the tertiary nitrogen atom of $\mathrm{CH}_{3} \mathrm{CN}$. The following rearrangement produces the acetyldiazonium ion. It is converted to the carbonium ion by the subsequent release of the nitrogen molecule. The carbocation reacts with the amino group on Guo, resulting in $N^{2}$-Ac-Guo. An alternative pathway in line with the pathway proposed for the reaction of Guo with $\mathrm{N}_{2} \mathrm{O}_{3}$ generating $\mathrm{Xao}$ and Oxo is shown in Path II. ${ }^{9,10)} \mathrm{N}_{2} \mathrm{O}_{3}$ reacts with the amino group on $\mathrm{C} 2$ of Guo, resulting in the $N^{2}$-nitroso intermediate. The nitroso intermedi-
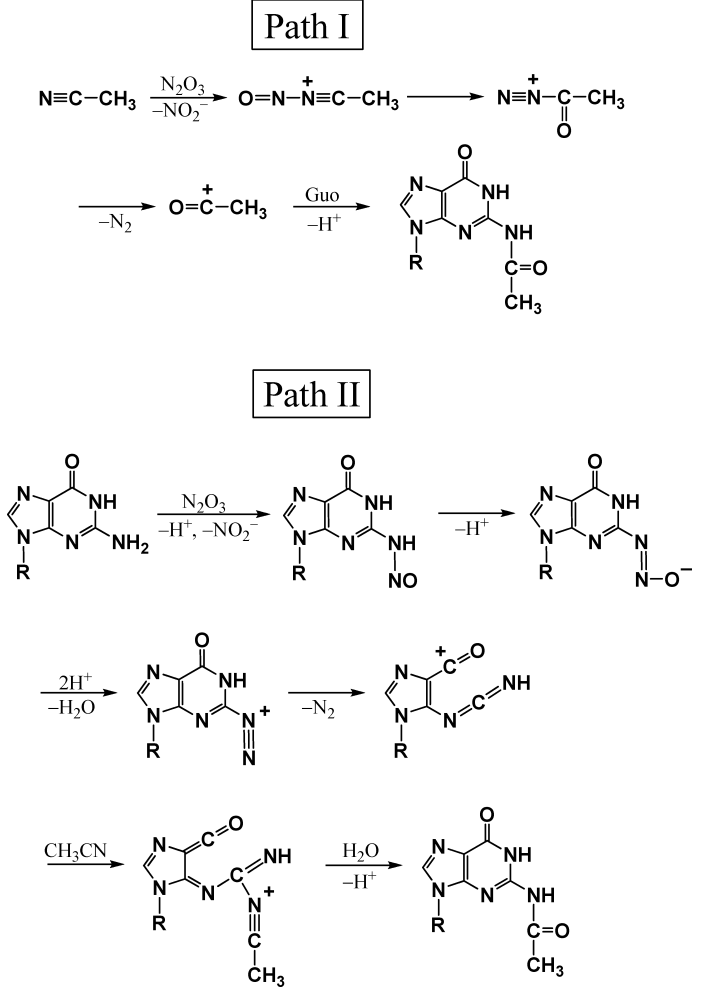

Chart 2. Two Conceivable Reaction Pathways for the Formation of $N^{2}$-AcGuo from Guo by the Reaction of $\mathrm{NO}$ and $\mathrm{CH}_{3} \mathrm{CN}$ under Aerobic Conditions

$\mathrm{R}$ in the structure denotes a ribose moiety

ate is converted to the diazonium intermediate $\left(-\mathrm{N}_{2}^{+}\right)$via the diazoate intermediate $\left(-\mathrm{N}=\mathrm{N}-\mathrm{O}^{-}\right)$. Then the ring-opened cation is formed synchronously by the release of a nitrogen molecule from the diazonium. The carbodiimide $(-\mathrm{N}=\mathrm{C}=$ $\mathrm{N}-$ ) of the ring-opened cation reacts with the lone pair on the tertiary nitrogen atom of $\mathrm{CH}_{3} \mathrm{CN}$, resulting in the adduct cation. It is converted to $N^{2}$-Ac-Guo by subsequent ring closure and addition of water. If path II is involved, the reaction is initiated by nitrosation of the exocyclic amino group of Guo. The $\mathrm{N}_{2} \mathrm{O}_{3}$ reaction of $N^{2}-\mathrm{Me}-\mathrm{Guo}$ in lieu of Guo should generate the relatively stable nitroso derivative, since $N^{2}$-MeGuo carries a secondary amine and, in general, the nitroso derivative of a secondary amine is stable. When $N^{2}$-Me-Guo ( $1 \mathrm{mg}$ ) was added into the $\mathrm{N}_{2} \mathrm{O}_{3} / \mathrm{CH}_{3} \mathrm{CN}$ solution, a product (compound 2) showing $\lambda_{\max }=240$ and $301 \mathrm{~nm}$ was detected on the RP-HPLC chromatogram (data not shown). The product was collected by RP-HPLC and subjected to an MS measurement. Figure 4 shows the ESI-TOF/MS spectrum on the negative mode of compound 2. Two peaks, $m / z 325$ and 295 , attributable to the molecular ion and the fragment ion produced by a loss of NO, respectively, were observed. The spectrometric data accorded well with the reported data of $N^{2}$-methyl- $N^{2}$-nitrosoguanosine $\left(N^{2}\right.$-Me- $N^{2}$-NO-Guo $){ }^{10)}$ This result suggests that the reaction of Guo with $\mathrm{N}_{2} \mathrm{O}_{3} / \mathrm{CH}_{3} \mathrm{CN}$ initiates by nitrosation of the amino group on Guo. If Path II is involved, the acetylated nitrogen atom of 2 position on $N^{2}$-Ac-Guo should originate from $\mathrm{CH}_{3} \mathrm{CN}$. To clarify the origin of the nitrogen atom of the exocyclic amino group on $N^{2}$-Ac-Guo, the reaction of Guo with $\mathrm{N}_{2} \mathrm{O}_{3} / \mathrm{CH}_{3} \mathrm{CN}$ was performed using ${ }^{15} \mathrm{~N}$ labeled $\mathrm{CH}_{3} \mathrm{CN}\left(\mathrm{CH}_{3} \mathrm{C}^{15} \mathrm{~N},{ }^{15} \mathrm{~N}\right.$ 


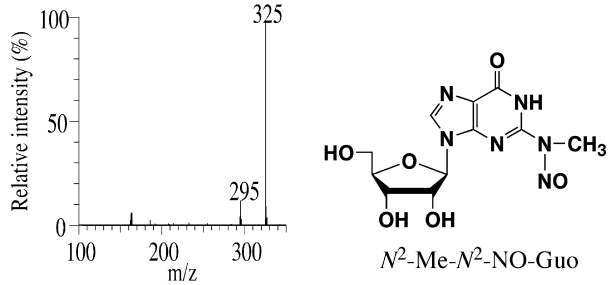

Fig. 4. Negative-Ion ESI-TOF/MS of 2 and the Structure of $N^{2}-\mathrm{Me}-N^{2}-$ NO-Guo

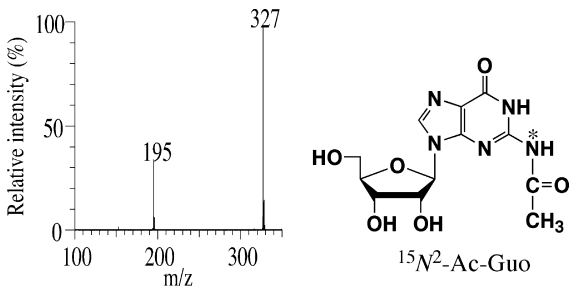

Fig. 5. Positive-Ion ESI-TOF/MS of $N^{2}$-Ac-Guo Generated from the Reaction in $\mathrm{CH}_{3} \mathrm{C}^{15} \mathrm{~N}$ and Its Structure

$98 \%+$, CIL, MA, U.S.A.). NO gas ( $4 \mathrm{ml} / \mathrm{min})$ was bubbled into $0.25 \mathrm{ml} \mathrm{CH}_{3} \mathrm{C}^{15} \mathrm{~N}$ in an open vessel at ambient temperature for $20 \mathrm{~min}$ under aerobic conditions. Guo $(2 \mathrm{mg})$ was added into the solution and left for $10 \mathrm{~min}$. The formed $N^{2}$ Ac-Guo was isolated by RP-HPLC. Its ESI-TOF/MS spectrum showed two major peaks, $m / z 327$ and 195, attributable to the molecular ion and the base fragment ion, respectively, (Fig. 5) which were one mass unit higher than those of the product in $\mathrm{CH}_{3} \mathrm{CN}$ (Fig. 3). This result indicates that the acetylated nitrogen atom on 2 position of $N^{2}$-Ac-Guo originated from $\mathrm{CH}_{3} \mathrm{CN}$ and that Path II is involved as a major path.

In conclusion, we propose the reaction mechanism for the formation of $N^{2}$-Ac-Guo in the reaction of Guo with $\mathrm{NO}$ in $\mathrm{CH}_{3} \mathrm{CN}$ under aerobic conditions as follows: $\mathrm{NO}$ reacts with $\mathrm{O}_{2}$ in the air resulting in $\mathrm{N}_{2} \mathrm{O}_{3}$ in $\mathrm{CH}_{3} \mathrm{CN}$. $\mathrm{N}_{2} \mathrm{O}_{3}$ reacts with the exocyclic amino group on Guo resulting in the $N^{2}$-nitroso derivative. The nitroso derivative is converted to the ringopened cation via the diazonium and diazoate intermediates. The carbodiimide of the ring-opened cation reacts with $\mathrm{CH}_{3} \mathrm{CN}$, resulting in the adduct cation. It is converted to $\mathrm{N}^{2}$ Ac-Guo by subsequent ring closure and addition of water.

\section{Experimental}

HPLC and MS Conditions The HPLC system consisted of Shimadzu LC-10ADvp pumps and an SCL-10Avp system controller. On-line UV spectra were obtained with a Shimadzu SPD-M10Avp UV-vis photodiode-array detector. An Inertsil ODS-3 octadecylsilane column of $4.6 \times 250 \mathrm{~mm}$ and particle size of $5 \mu \mathrm{m}$ (GL Science, Tokyo) was used. The eluent was $20 \mathrm{~mm}$ ammonium acetate buffer ( $\mathrm{pH}$ 7.0) containing methanol. The methanol concentration was increased from 0 to $50 \%$ over $15 \mathrm{~min}$ in linear gradient mode and kept at $50 \%$ until $30 \mathrm{~min}$. The column temperature was $40{ }^{\circ} \mathrm{C}$ and the flow rate was $1.0 \mathrm{ml} / \mathrm{min}$. The ESI-TOF/MS measurements were performed on a MicroTOF spectrometer (Bruker, Bremen, Germany) in the positive mode. The sample isolated by RP-HPLC using $20 \mathrm{~mm}$ ammonium acetate buffer ( $\mathrm{pH}$ 7.0) containing methanol as the eluent was directly infused into the MS systems by a syringe pump without a column at a flow rate of $2 \mu \mathrm{l} / \mathrm{min}$.

Spectrometric Data of $\boldsymbol{N}^{2}$-Acetylguanosine $\left(\boldsymbol{N}^{2}\right.$-Ac-Guo) ${ }^{1} \mathrm{H}-\mathrm{NMR}$ $\left(500 \mathrm{MHz}\right.$, in DMSO- $d_{6}$ at $\left.25^{\circ} \mathrm{C}\right) \delta(\mathrm{ppm} / \mathrm{TMS}): 12.04(\mathrm{~s}, \mathrm{NH}, 1 \mathrm{H}), 11.71$ (s, NH, 1H), 8.24 (s, H8, 1H), $5.78\left(\mathrm{~d}, \mathrm{H}^{\prime}, 1 \mathrm{H}\right), 5.47$ (br, OH, 1H), 5.17 (br, $\mathrm{OH}, 1 \mathrm{H}), 5.02(\mathrm{br}, \mathrm{OH}, 1 \mathrm{H}), 4.42\left(\mathrm{dd}, \mathrm{H}^{\prime}, 1 \mathrm{H}\right), 4.11\left(\mathrm{dd}, \mathrm{H}^{\prime}, 1 \mathrm{H}\right), 3.89(\mathrm{~m}$, $\left.\mathrm{H} 4^{\prime}, 1 \mathrm{H}\right), 3.58\left(\mathrm{~m}, \mathrm{H} 5^{\prime}, 5^{\prime \prime}, 2 \mathrm{H}\right), 2.17\left(\mathrm{~s}, \mathrm{CH}_{3}, 3 \mathrm{H}\right) ;{ }^{13} \mathrm{C}-\mathrm{NMR}(125 \mathrm{MHz}$, in DMSO- $d_{6}$ at $\left.25^{\circ} \mathrm{C}\right) \delta(\mathrm{ppm} / \mathrm{TMS}): 173.4\left(\mathrm{CH}_{3} \mathrm{CO}\right), 154.7,148.7,147.9$ $137.5(\mathrm{C} 8), 120.1,86.5\left(\mathrm{C} 1^{\prime}\right), 85.2\left(\mathrm{C}^{\prime}\right), 73.9\left(\mathrm{C}^{\prime}\right), 70.1\left(\mathrm{C}^{\prime}\right), 61.0\left(\mathrm{C}^{\prime}\right)$, $23.7\left(\mathrm{CH}_{3} \mathrm{CO}\right.$ ); UV: $\lambda_{\max }=259 \mathrm{~nm}(\mathrm{pH} 7.0$ ); ESI-TOF/MS (positive) $\mathrm{m} / \mathrm{z} 326$ $[\mathrm{M}+\mathrm{H}]^{+}, 194\left[\mathrm{M}_{\text {base fragment }}+\mathrm{H}\right]^{+}$.

Spectrometric Data of $N^{2}$-Methyl- $N^{2}$-nitrosoguanosine $\left(N^{2}-\mathrm{Me}-N^{2}\right.$ NO-Guo) UV: $\lambda_{\max }=240,301 \mathrm{~nm}(\mathrm{pH} 7.0$ ); ESI-TOF/MS (negative) $\mathrm{m} / \mathrm{z}$ $325[\mathrm{M}-\mathrm{H}]^{-}, 295[\mathrm{M}-\mathrm{NO}-\mathrm{H}]^{-}$.

\section{References and Notes}

1) Present address: Hayashi Hospital, Okayama 703-8520, Japan

2) Marletta M. A., J. Biol. Chem., 268, 12231-12234 (1993).

3) Bredt D. S., Synder S. H., Annu. Rev. Biochem., 63, 175-195 (1994).

4) Zhao K., Whiteman M., Spencer J. P., Halliwell B., Methods Enzymol., 335, 296-307 (2001).

5) Williams D. L. H., "Nitrosation Reactions and the Chemistry of Nitric Oxide," Elsevier, Amsterdam, 2004

6) Wink D. A., Kasprzak K. S., Maragos C. M., Elespuru R. K., Misra M., Dunams T. M., Cebula T. A., Koch W. H., Andrews A. W., Allen J. S., Science, 254, 1001-1003 (1991).

7) Nguyen T., Brunson D., Crespi C. L., Penman B. W., Wishnok J. S., Tannenbaum S. R., Proc. Natl. Acad. Sci. U.S.A., 89, 3030-3034 (1992).

8) Suzuki T., Yamaoka R., Nishi M., Ide H., Makino K., J. Am. Chem. Soc., 118, 2515-2516 (1996).

9) Glaser R., Son M.-S., J. Am. Chem. Soc., 118, 10942-10943 (1996).

10) Suzuki T., Ide H., Yamada M., Endo N., Kanaori K., Tajima K., Morii T., Makino K., Nucleic Acids Res., 28, 544-551 (2000).

11) Lucas L. T., Gatehouse D., Shuker D. E., J. Biol. Chem., 274, 18319 18326 (1999).

12) Mason J., J. Chem. Soc., 1959, 1288-1295 (1959).

13) Shaw A. W., Vosper A. J., J. Chem. Soc., Dalton Trans., 1972, 961964 (1972).

14) Fan Y., Gaffney B. L., Jones R. A., Org. Lett., 6, 2555-2557 (2004). 